\title{
THE ORGANISATION OF POLYGENIC ACTIVITY WITHIN A CHROMOSOME IN DROSOPHILA
}

\author{
I. HAIR CHARACTERS \\ E. L. BREESE AND K. MATHER \\ Agricultural Research Council Unit of Biometrical Genetics, \\ Department of Genetics, University of Birmingham
}

Received $16 . i 1.57$

THE response of a population of living organisms to the impact of any force of selection will vary not only with the nature of the force itself but also with the genetical architecture of the character or characters in question. The genetical architecture of a character will of course reflect those general properties which together constitute the genetic system of the population and species (Darlington, I939, 1956): the system of reproduction, whether asexual, subsexual, sexually inbreeding or sexually outbreeding; and the number, organisation and relations of the chromosomes especially as reflected in the properties of genic recombination. At the same time, the architecture will depend on the detailed organisation (both mechanically in hereditary transmission, and physiologically in developmental action) of the system of genes mediating its expression, or rather the variation in that expression. Furthermore, in considering the organisation of the genic system, and particularly the polygenic system, mediating the variation in one character we cannot neglect its relation to the genic systems affecting other characters, for selective response in the one will be conditioned by any effect it may have in dragging other characters with it, whether because of the linkage relations of the two gene systems along the chromosomes or of their physiological relations in action. All these things must be taken into account if we are to understand response to selection; and each will tell us something of the past action of selection, for the systems and organisations we see to-day will be those which have successfully survived the test of selection in the past.

At present we have little detailed knowledge of the organisation and properties of polygenic systems in these respects. Selection experiments have told us something of their overall properties in a number of species, particularly Drosophila and mice ; and, in Drosophila, chromosome assays and similar techniques have shown us broadly how the polygenic system is characteristically distributed over all the chromosomes, how its member genes in different chromosomes can interact in producing their effects, and how interactions can be seized on by selection. About the distribution within chromosomes and the relation of interactions to that distribution, however, little is known. Early analysis (Mather, 1942, and see review by Wigan, I949a) did little more than show that the problem existed, though 
in his own experiments Wigan was able to establish the occurrence of polygenic activity along the whole length of the $\mathrm{X}$ chromosome of Drosophila. More detailed and more precise information is, however, needed about both gene distribution and gene interaction if we are to understand the consequences of selection or to obtain the insight into gene structure and function that such studies offer (Mather, I954). The present paper and its companions report an investigation aimed at supplying information of this kind.

\section{CONSTRUCTION AND USE OF THE RECOMBINANT CHROMOSOMES}

Investigation of the distribution of polygenic activity along a chromosome requires the use of marker genes to enable particular segments of the chromosome to be identified and followed in the breeding experiments. In past experiments these marker genes have been used directly to identify the presence of recombinants whose effects on the expression of the primary character could then be assessed immediately without further breeding. This direct approach is convenient and relatively quick but it suffers from certain drawbacks, notably that the marker genes themselves sometimes disturb the character in question so that assessment of the effect of the segments of chromosome they mark becomes difficult, and that it is impossible to investigate fully the interactions in effect of the different segments. A different technique was therefore used permitting the construction, storage and subsequent use of recombinant chromosomes from which all marker genes had been eliminated.

The investigation was begun from two stocks, one selected for high and the other for low number of abdominal chaetæ. The former, which will be denoted as $\mathrm{H}$, was descended by mass mating from the $8 \times 9$ line of Mather and Harrison (1949), and the latter, which will be denoted as L, was descended from the LL line of Harrison (I953). The average chaeta numbers of the two were found to be $\mathrm{H} 6 \mathrm{I} \cdot 46 \pm$ 0.45 and $\mathrm{L}_{36} \cdot \mathrm{I} 9 \pm 0 \cdot 14$. A small chromosome assay of the customary type traced a difference of 4.80 chaetæ to genes in the $\mathrm{X}$ chromosome, one of 3.35 chaetæ to genes in chromosome II and one of 8.20 chaetæ to chromosome III, a total of 16.35 chaetæ where on an average no more than half the parental difference is expected to be assignable to chromosomes by this type of assay. Attention was therefore concentrated on chromosome III as offering the largest genetical difference for analysis.

Both $\mathrm{H}$ and $\mathrm{L}$ were crossed to a stock carrying the so-called " rucuca" chromosome III, which bears the genes $r u, h$, th, st, cu, $s r, e^{s}, c a$ marking its whole length (see fig. I). The genes th and st are, however, so close together on the genetical map that it was found preferable to treat them as a single composite locus, the rare recombinations between them being discarded. This composite locus is referred throughout as st, and the average limits of the origins shown 
in fig. I have been determined from the position of st. This will not disturb the right limits of regions $\mathrm{B}, \mathrm{P}$ and $\mathrm{X}$ but will mean that the left limits of these regions are shown just under half a unit too far to the right-a difference which must be small when compared with the intrinsic variation in the position of the effective point of crossingover. Heterozygous females of both types, $\frac{H}{\text { rucuca }}$ and $\frac{\mathrm{L}}{\text { rucuca }}$, were backcrossed to rucuca males, so that recombinant chromosomes consisting partly of the $\mathrm{H}$ (or L) chromosome III and partly of the rucuca chromosome III could be recognised. Thereafter the procedure varicd in detail with the particular type of recombinant chromosome aimed at, but in general it was the same for all and it will be illustrated

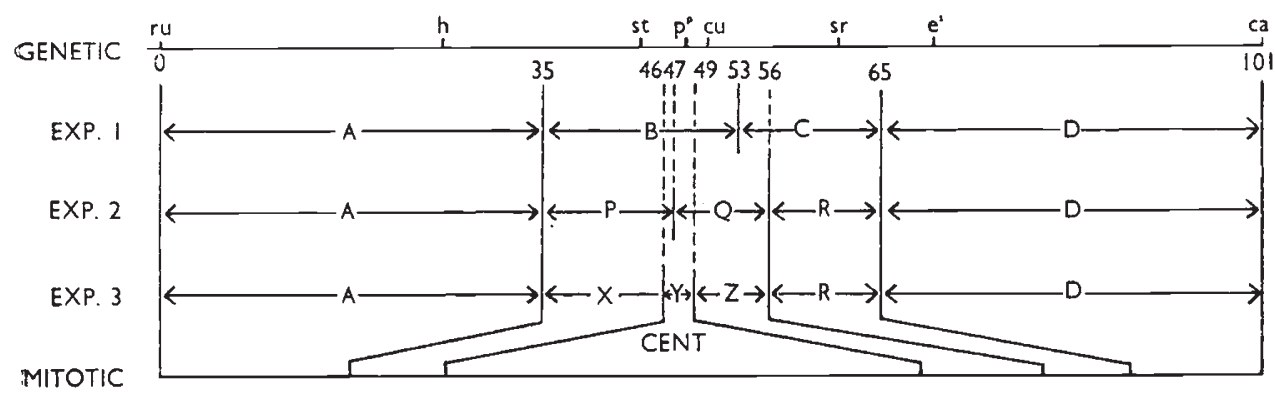

Fig. 1.- The genes used in constructing the wild-type chromosomes and the segments of which, in consequence, thesc chromosomes were constructed (see in the text).

The extent of cach segment is indicated by the arrows, the limits being shown in their average positions. Apart, however, from the left of $\mathrm{A}$ and the right of $\mathrm{D}$, the limits might fall by the vagaries of recombination anywhere between the straddling genes (e.g. the right limit of $\mathrm{A}$ might come anywhere between $h$ and $s t$ ) the average position being midway between them on the genetical map. This variation in position of recombination could also lead to a small piece of the marked chromosone being inserted in the region of the limit.

The average position of all the limits are indicated in relation to the genetical map (above) and of some of them also in relation to the mitotic cytological map (bclow). The general position of the centromere (Cent.) is shown on the mitotic map. though it may well be nearer to the left limit of region $Y$ than is indicated. All positions on this map are very approxinate.

by reference to the construction of chromosomes showing recombination between $h$ and st. From the progeny of backcrossing $\frac{\mathrm{H}}{\text { rucuca }}$ to rucuca a fly of the phenotype st cu sr $e^{s} c a$ and therefore of genotype

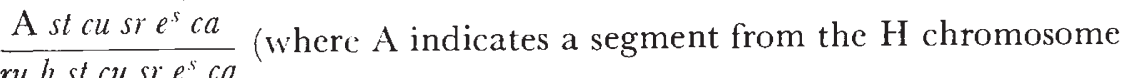
III covering the $r u$ and $h$ loci) was selected and mated to a fly from the $\frac{\mathrm{L}}{\text { rucuca }}$ backcross of the opposite sex and of phenotype $r u h$ and therefore of genotype $\frac{r u h \mathrm{bc} \mathrm{d}}{r u h s t c u s r e^{s} c a}$, where b c d represent a segment of the L chromosome III covering the st cu es ca loci. Wildtype daughters which must be of the constitution $\frac{\mathrm{A} s t c u s r e^{s} c a}{m h \mathrm{~h} \mathrm{~cd}}$ were 
taken and crossed again to rucuca males. The wild-type progeny of this cross must bear a chromosome combining a segment of $\mathrm{H}$ at the left end and a segment of $\mathrm{L}$ at the right end, the junction lying between $h$ and st with possibly a short piece of chromosome from rucuca interposed between $H$ and $L$ segments. A male of this type was then mated to a stock having its two chromosomes III marked by $M e S b$ and $H$ (= gene Hairless) respectively. The recombinant chromosome can then be held in the male line, sheltered from further recombination, by crossing $M e S b / H$ females to $M e S b /$ recombinant males in every generation. The desired wild-type chromosome,

TABLE I

The recombinant wild-type chromosomes constructed and used in the experiments. Capital and small letters indicate segments derived from chromosome III of the $H$ and $L$ lines respectively. The limits of the segments denoted by $A-a, B-b$, etc. are shown in fig. $I$. In Group (c) the constitution in respect of segment $D-d$ is not fully certain as the gene ca was omitted from the marked chromosome used in the process of construction.

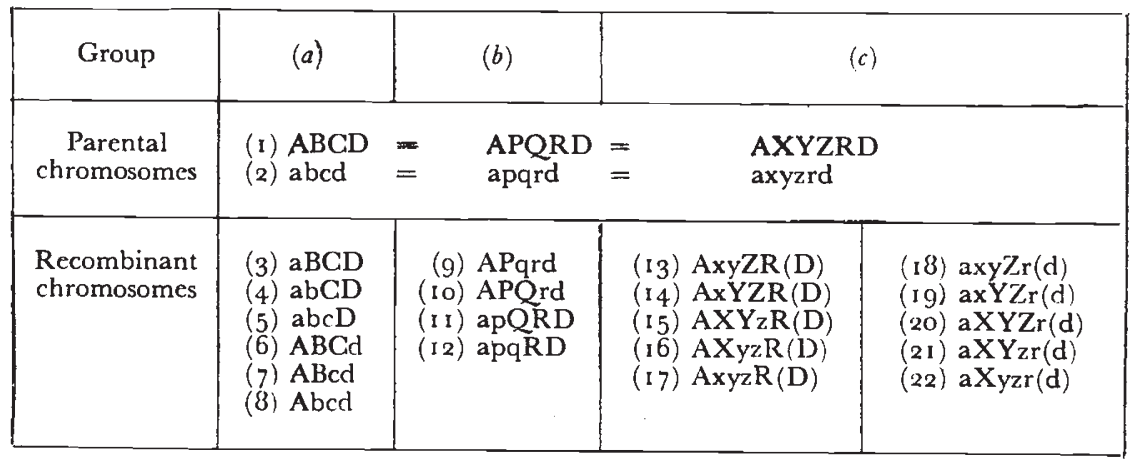

composed of known pieces from the $\mathrm{H}$ and $\mathrm{L}$ chromosome III, has been constructed and put into store.

Recombinant chromosomes were constructed in three separate rounds. In the first round a modified rucuca chromosome was used from which $c u$ was omitted for reasons which need not detain us. No recombinants were selected in the end segments between $r u$ and $h$ or $e^{s}$ and $c a$, so that the chromosome was being treated in effect as consisting of the four segments A, B, C and D as shown in fig. I. The end points of the segments are of course not sharply defined since the right end of segment $\mathrm{A}$, for example, may come anywhere between $h$ and st and need not in fact coincide exactly with the left end of scgment B. Thus chromosomes which are grossly similar in terms of the segments they have derived from $\mathrm{H}$ and $\mathrm{L}$, need not agree precisely in the points at which recombination has fixed the ends. The average position of the end will be the mid point of the two marker genes on the genetical map. The recombinant chromosomes of table I $(a)$ were constructed in this way, two separate and distinct chromosomes of each type being made up on this and all later occasions. Capital letters indicate segments from the $\mathrm{H}$ stock and small letters the corresponding segments from $\mathrm{L}$. 
In the second round a usable rucuca chromosome was available carrying $c u$. The use of $c u$ as a marker between st and $s r$ enables the two segments, $\mathrm{B}$ and $\mathrm{C}$ of the previous occasion to be broken up into three, denoted as $\mathrm{P}, \mathrm{Q}$ and $\mathrm{R}$ in the way shown in fig. $\mathrm{I}$. Four types of chromosome were built up as shown in table $I(b)$.

A further gene, $p^{p}$, was introduced into the marked chromosome for the third round of chromosome building, the gene $c a$ being left out so as to avoid difficulties of classifying the flies. The introduction of $p^{p}$ enables the segments $\mathrm{P}$ and $\mathrm{Q}$ to be jointly broken down into three segments, denoted by X, Y and Z (fig. I). Ten types of chromosome were constructed as shown in table $\mathrm{r}(c)$. Since $c a$ was omitted, the status of the chromosomes was not fully clear in respect of part of segment $D$.

The various recombinant chromosomes were tested for their effects on the various characters chiefly in sets of diallel crosses, as will be detailed later. In respect of chromosome III the crosses used in these cliallels were always of the type $\frac{\mathrm{I}}{M e S b} \times \frac{\mathrm{J}}{H}$ where I and $\mathrm{J}$ indicate any two of the recombinant chromosomes. The Me Sb chromosome materially reduces, if it does not wholly suppress, recombination in the female parent, so preserving the identity of chromosome I. Such a cross gives four types of progeny $\frac{M e S b}{H} ; \frac{\mathrm{J}}{M e S b} ; \frac{\mathrm{I}}{H} ; \frac{\mathrm{I}}{\mathrm{J}}$. The last class of flies, which is of course wild type, provides the material for assessing the joint effect of the $\mathrm{I}$ and $\mathrm{J}$ chromosome on the various characters such as chaeta number. The first type appears in all crosses and therefore affords a yardstick for the measurement of the effects of the recombinant chromosomes on the viability of their carriers.

The background of $\mathrm{X}$ and II chromosomes was held constant or virtually so within each diallel set, coming either from the $\frac{\mathrm{Me} S b}{H}$ stock (and denoted as the M background) or the Oregon stock (and denoted as the $\mathrm{O}$ background). The recombinant chromosomes were placed on the $\mathrm{M}$ background by backcrossing into the marked stock. Both these and the marked chromosomes were placed on the $\mathrm{O}$ background in the same way. At least four generations of backcrossing were used in every case.

\section{THE FIRST EXPERIMENT}

This was based on a set of diallel crosses including all the chromosomes (I)-(8), with the exception of (2), as listed in table $\mathrm{r}$. Every chromosome was introduced from the mother into combination with every chromosome from the father. With 7 chromosomes there are thus 49 combinations of which 7 are homozygotes. The 42 heterozygous combinations fall into $2 \mathrm{r}$ pairs, the members of a pair differing 
according to which of the two chromosomes came in from mother and father respectively. The differences between the members of these pairs afford information about differences between reciprocal crosses, and provided such reciprocal differences are small the members of a pair can be pooled for comparison with the other combinations, both heterozygous and homozygous.

The diallel set was made up four times on separate occasions, twice with one group of recombinant chromosomes and twice with a second group formally like the first in respect of segments A-a, B-b, C-c and D-d, but constructed separately so that they may differ from the first group as a result of the normal variation in the position of crossing-over between the marker genes. 'Two diallel sets were made with the $\mathrm{M}$ and two with the $\mathrm{O}$ backgrounds, backgrounds and groups of chromosomes being combined in all ways, thus, $M$ background-Ist group, $\mathrm{M}$ background-2nd group, $\mathrm{O}$ backgroundIst group, $\mathrm{O}$ background-2nd group. The numbers of chaetæ on the $4^{\text {th }}$ and $5^{\text {th }}$ abdominal segments, and the numbers of sternopleural chaetæ on both sides of the fly were counted on Io wild-type females and on Io wild-type males of each combination. In I 4 cultures fewer than the normal io flies of each sex were obtained and the reduced numbers of flies had to be accepted as the basis for evaluation in these cases. The combination (4) (3) failed completely in the third diallel set. The relevant mean numbers of chaetæ were then estimated by the missing-plot technique based on reciprocal differences. All the calculations to be described were made using as data the mean number of abdominal chaetæ on the $4^{\text {th }}$ and $5^{\text {th }}$ segments together, or the mean number of sternopleural chaetæ on the two sides together, from the io females and Io males of each combination.

A preliminary analysis of each diallel set was made by the calculation and comparison of the array variances $(V)$ and covariances within arrays of family mean and non-recurrent parent (W) described by Hayman (1954b) and Jinks (1954). The W/V graphs calculated from the overall means of the combinations, obtained by averaging each combination over sexes, backgrounds and groups (fig. 2), showed no significant departure from a straight regression line of unit slope, though the points did suggest a slight curvature, which is fairly attributable to the partial association of the different alternative segments in the parental recombinant chromosomes. A further graphical comparison was made between the covariance (W) described above and a further covariance $\left(\mathrm{W}^{1}\right)$, similar to it and again calculated within the array, but relating the family mean not to the non-recurrent parent but to the mean of all offspring of that parent (Hayman, unpublished). Interaction reveals itself in such a graph (fig. 2) by departure of the regression of $W$ on $W^{1}$ from a line of slope 2. In the present case the slope falls a little below this expectation, but the discrepancy may reasonably be attributed to inequality of the frequencies with which alternative segments, such as $\mathrm{A}$ and a appear 


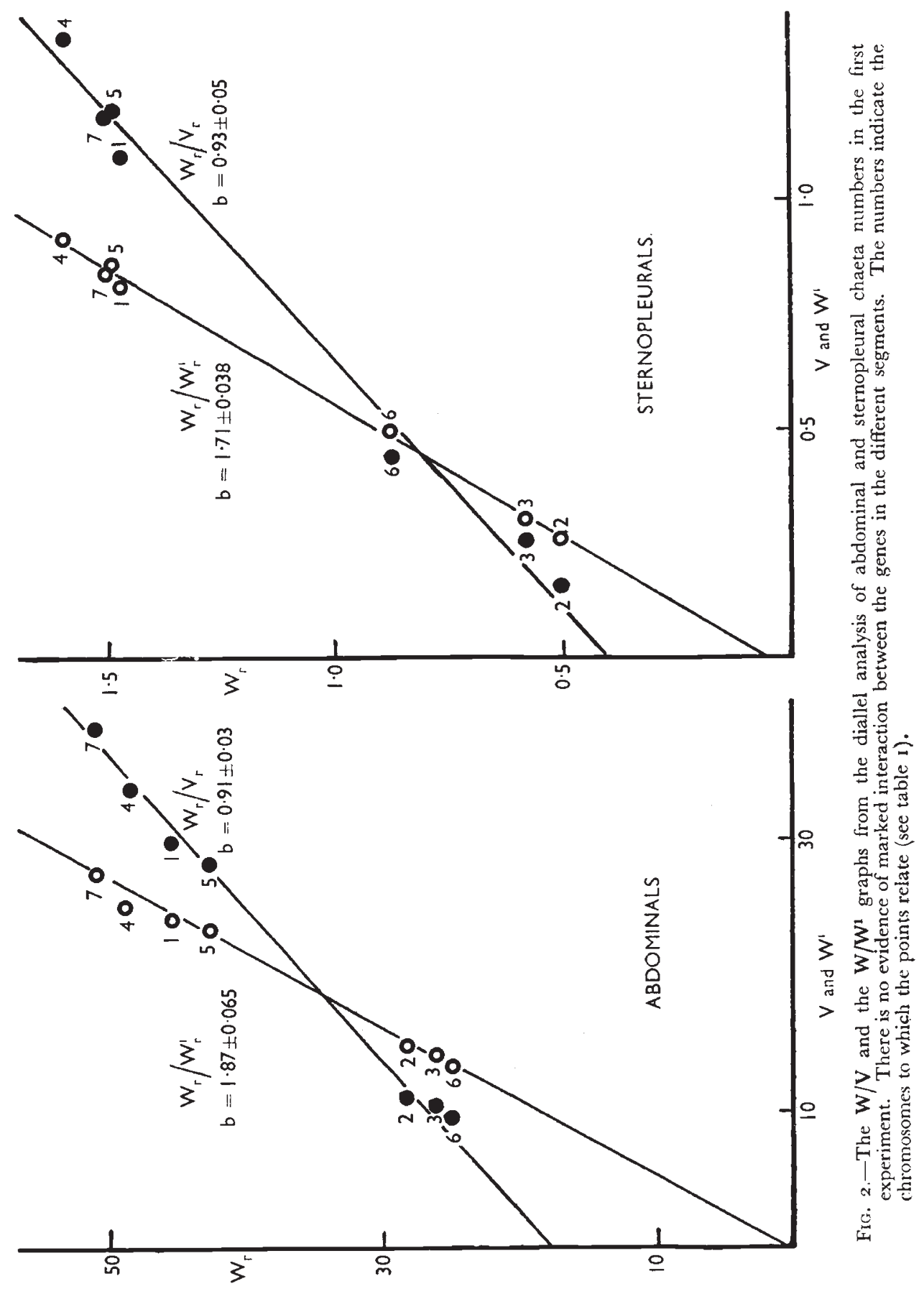


among the seven chromosomes used in the diallel. There is in any case no evidence of any marked interaction among the genes of the different segments in producing their effects, though there is clear evidence of dominance, chiefly of the segments stemming from the $\mathrm{L}$ line over their alternatives from $\mathrm{H}$.

The main analysis, however, was carried out in a different way. Two constants were assigned to each of the four segments in respect of each chaeta character, one representing the contribution of that segment to the additive variation in respect of the chaeta character in question and the other representing its contribution to the dominance variation, in the way described by Mather (1949). These additive constants were denoted by $\mathrm{d}_{\mathrm{a}}, \mathrm{d}_{\mathrm{b}}, \mathrm{d}_{\mathrm{c}}$ and $\mathrm{d}_{\mathrm{d}}$, and the dominance constants by $h_{a}, h_{b}, h_{c}$ and $h_{d}$, where the subscripts a-d refer to the four segments so lettered in table I. Since the segments are not distributed orthogonally among the chromosomes used in the experiment, the least squares technique was used to make estimates of the values of these various constants from the mean numbers of chaetæ observed for the various combinations. Given these estimates, expected values can then be calculated for the mean of each combination of chromosomes and compared with the mean hair numbers actually observed. When squared and summed the differences between the expected and observed values provide sums of squares which can be used to carry out an analysis of variance testing the significance of (i) the contribution to the additive and dominance variation, (ii) any residual effects which are to be attributed to interaction between the genes of the different segments, and (iii) the variation of the effects with sexes, backgrounds and groups of chromosomes.

In general this analysis of variance proceeds along the lines described by Mather (1949) and Mather and Vines (1952), though it should be observed that the present analysis is of first degree statistics by constants which are linear measures of variation and so can take sign, while the earlier analyses were of second degree statistics by quadratic constants which of course could not take sign. Two further points require to be made about the analyses. First, three fitting operations were carried out using different numbers of constants. In the first operation only the four $d$ constants were fitted, the sum of squares taken out being that referable to the contribution to additive variation alone. In the second, the $h_{b}$ constant was fitted in addition to the four d's, thus including an allowance for dominance in region $\mathrm{B}-\mathrm{b}$ which makes the largest contribution to the additive variation and which most likely included the centromere and the regions of chromosome immediat'ly adjacent to it on the linkage map. The extra sum of squares taken out by fitting these five constants over that taken out by the four d's measures the effect of dominance in region B-b. Finally all eight constants were fitted simultaneously. The sum of squares taken out in excess of that accounted for by the five constants of the second fitting operation measures the effect of 
dominance in the remaining three segments jointly. The ascription of degrees of freedom to these sums of squares is straightforward. Pooling reciprocal pairs of heterozygous combinations leaves $28 \mathrm{com}$ binations, 7 homozygous and 21 heterozygous, which will provide 27 degrees of freedom for differences amongst them. Fitting four constants uses up 4 of these degrees of freedom, five constants use up 5, and eight constants use up 8 . Thus the sum of squares for the contribution to additive variation found from the first fitting corresponds to 4 degrees of freedom, the additional sum of squares for dominance in B-b to 1 d.f., and the additional sum of squares for dominance in the other three segments to 3 d.f., lcaving $27-4-1-3=$ 19 for the residual sum of squares depending on genic interaction between the segments.

The second point to be made concerns the calculation of the sums of squares for change in the various components of variation (the additive, dominance and residual interaction) with sex, background and group. To take variation with sex as an example, the constants can be fitted and the sums of squares for the components of variation calculated both on data pooled over sexes and on the data for the individual sexes separately. The two sums of squares for, say, the additive component from the individual sexes, when added together give a total which will include both the sum of squares for the overall additive component and also the sum of squares for difference between the additive components of the two sexes. The former item is known from the calculation based on the data pooled over sexes and the latter item can be found by subtraction. This process is, of course, exactly analogous to the calculation of "interaction" items in the computational procedure of the standard analysis of variance and has indeed been used and described fully in its present form by Mather and Vines (1952). It can be cxtended to calculations of the more complex variation of the components of variation with sexes, backgrounds and groups of chromosomes in a way parallel to that used in the standard procedure of analysis of variance.

This procedure covers all items in the analysis of variance except that for reciprocals. The sum of squares for differences between reciprocal crosses can be found by the procedure described by Hayman (1954a) for diallel cross analysis. This can be broken down into two items by Hayman's procedure, and the variation of reciprocal differences with sex, etc. can be found; but these items have not been presented separatcly in the present analysis as they are homogeneous with one another. There are two less degrees of freedom for reciprocals than might be expected at first sight, since two have been lost in estimating the values for the two sexes in the missing culture, already noted, by minimisation of the reciprocal sums of squares.

The eight constants are shown averaged over sexes, backgrounds and groups in table 2, the figures given being, of course, those obtained when all eight constants were fitted simultaneously to the particular 
subdivision of the data in question. The analysis of variance is given in table 3 as Mean Squares for each item. These tables include results for both abdominal and sternopleural chaetæ.

TABLE 2

The constants measuring the additive and dominance contributions of the four regions to variation in the first experiment

\begin{tabular}{|c|c|c|c|c|c|c|c|c|c|}
\hline & $\mathrm{d}_{\mathrm{a}}$ & $d_{b}$ & $d_{c}$ & $d_{d}$ & $\mathrm{~h}_{\mathrm{a}}$ & $h_{b}$ & $h_{c}$ & $h_{d}$ & s.e. \\
\hline Abdominals & $1 \cdot 63^{*}$ & $7 \cdot 16^{*}$ & $1 \cdot 02 *$ & $1 \cdot 55^{*}$ & $0.55^{*}$ & $-2 \cdot 32 *$ & -0.17 & $0.75^{*}$ & 0.26 \\
\hline Sternopleurals & $0.24 \dagger^{\dagger}$ & $1 \cdot 27^{*}$ & 0.15 & $0.32 *$ & $-0.3^{*}$ & $-0.54^{*}$ & 0.07 & -0.03 & 0.10 \\
\hline
\end{tabular}

There is clear cvidence from the analysis of variance that the additive component of variation, the dominance component for region $\mathrm{B}-\mathrm{b}$ and the dominance component for the other regions jointly are significant in both abdominals and sternopleurals. In the abdominals

TABLE 3

Analysis of variance of results from the first experiment

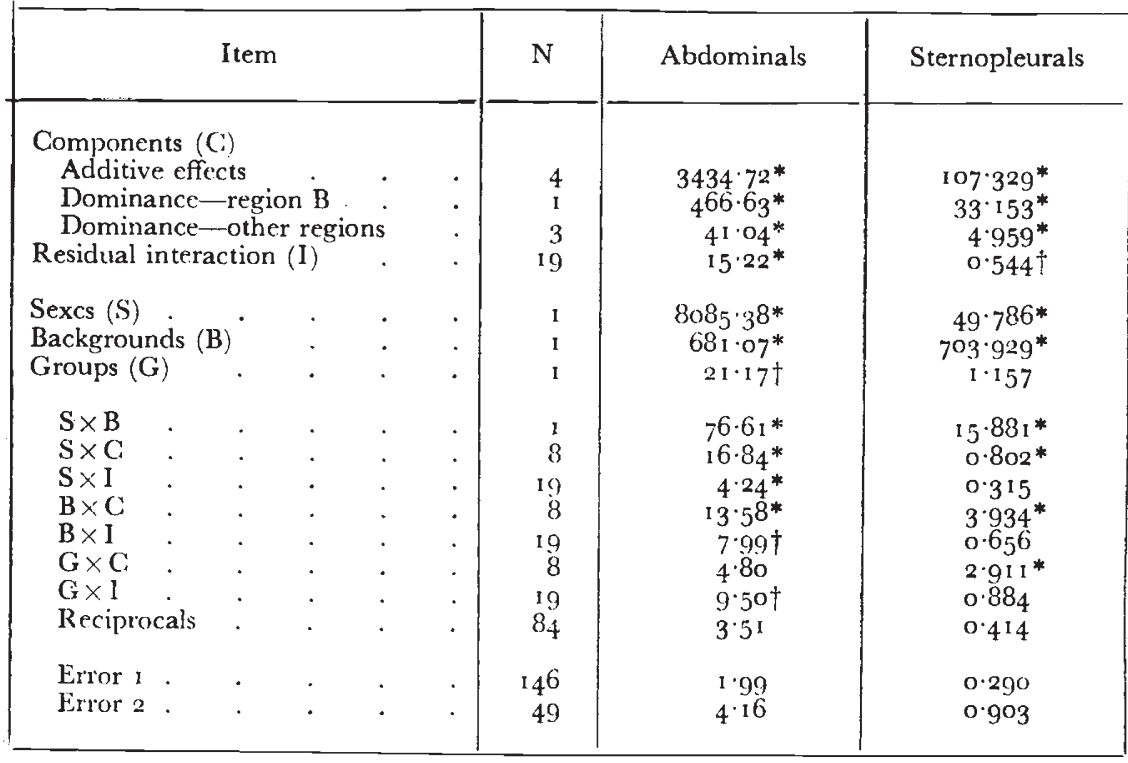

For the applicability of the two error variances, see text.

$$
\text { * } \mathrm{P}<0.01 \text {. } \quad+0.01<\mathrm{P}<0.05 \text {. }
$$

the item for residual interaction is also significant, so that in respect of this character the genes in the different segments clearly show some interaction in producing their effects. This item for interaction is less clearly significant in the sternopleurals but even here it is at least suggestively large.

Turning next to sexes, backgrounds and groups, a caution must be introduced immediately. The sex difference and its relation to 
the components of variation is measured by comparisons within each of the four parts of the experiment distinguished by background and group. The effects of these latter were, however, found by comparison between these four parts. As already noted these four parts were carried out on different occasions and so may show differences also as a result of any changes which may have occurred in the environment. Thus different estimates of error variation must be used in testing the relations of components to sex and of components to background and group. The error variance for testing the sex difference and the items showing its relation to components, background groups and so on may thus be found from the triple interaction (in the statistical sense) between components, sex and background and components, sex and groups, and from the quadruple interaction. These are similar in value to one another and are pooled as error (I) in the table. The error variance for the items relating backgrounds and groups to components is to be found from the triple interaction of components, backgrounds and groups shown as error (2) in the table. The main items for background and groups should strictly be tested against the sum of squares for their statistical interaction, but this has only I degree of freedom and so is of little use as an error variance. Its mean square of 6.5 for abdominals and 0.990 for sternopleurals is close to that of error (2) which has therefore been used in its place and in which it is indeed included.

The sex difference in abdominals requires no testing: it is a striking feature of the results and is already well known. When tested against the appropriate error variances it is clear that the genetic background has a marked effect on abdominal chaeta number. There is a good indication, too, that the mean square from groups, with a probability of about 0.02 , is significantly large. Evidently similar chromosomes constructed on different occasions are not exactly alike in their genic contents, doubtless because of differences in the position of crossing-over within the marked segments. Continuing down the analysis of variance, the sex difference clearly varies with the background (item $\mathrm{S} \times \mathrm{B}$ ), and the additive and dominance components vary significantly in value with $\operatorname{sex}(\mathrm{S} \times \mathrm{C})$. There is also evidence that the residual genic interactions vary with sex $(\mathrm{S} \times \mathrm{I})$, though perhaps to a lesser extent. The additive and dominance components vary also with background $(B \times C)$ but there is no evidence of their variation with group $(\mathrm{G} \times \mathrm{C})$. The residual genic interaction appears to vary with both background $(B \times I)$ and group $(G \times I)$. This last result suggests that components, too, may well vary with group even though this present analysis has failed to reveal it. It is noteworthy that the mean squares for residual interaction and for the variation of components with sex and background are of closely similar magnitude. Since $\mathrm{S} \times \mathrm{C}$ and $\mathrm{B} \times \mathrm{C}$ test the relation of the components springing from genes in chromosome III with those of other chromosomes, they too depend on genic interaction. The indications are 
thus that the interaction of genes within chromosome III are of the same order of effect on abdominal chaeta number as the interaction of genes in different chromosomes. There is no good evidence of differences between reciprocal heterozygotes.

The additive and dominance components can be investigated further by considering the values of the constants which were fitted. Table 2 sets out the estimated values of the four $d$ and the four $h$ items for both abdominals and sternopleurals. The eight parts of the experiment distinguished by sex, background and group each yielded a value for $d$ and $h$. The values shown are means taken over the eight parts. These are tested for departure from zero, the value expected in the absence of genetic effect, by comparison with a common standard error based on the differences among the eight estimates of each constant. Each constant provides seven such differences so that the overall standard error appears to be based on $7 \times 8=5_{5}^{6}$ degrees of freedom. This is, however, an overestimate of the number of degrees of freedom, since not all of the 56 comparisons are fully independent of each other. It is, however, hardly worth the attempt to allow for this dependence, as even only half this number of error degrees of freedom would be sufficient to give a good test of the constants.

For the abdominal chaetæ each of the four d's is significantly larger than zero, and each is positive showing that, as might be expected, the segment derived originally from the $\mathrm{H}$ line has a higher chaetaproducing effect than its alternative from $\mathrm{L}$. Thus all segments are genically active but B-b contributes more to the additive variation than do all the other three segments put together. The dominance effects are smaller, but again all but $h_{c}$ are at least suggestively large, that from B-b being once more especially striking. Not all the dominance is in the same direction.

The segment B-b also has the greatest effect on sternopleural number in both $d$ and $h$. D-d makes a clear contribution to the additive variance and A-a a very suggestively large one, but there is no good evidence of an effect in C-c. A-a makes a significant contribution to the dominance component of variation in sternopleurals but C-c and D-d show no clear effect on dominance. Again the $h$ items vary in direction of the dominance they reveal.

\section{THE SECOND EXPERIMENT}

This was designed as a set of diallel crosses involving eight chromosomes, viz. (3), (5), (6), (8), (9), (ro), (I I) and (I 2) of table I. The diallel was set up twice, the background being $M$ in both cases. Each diallel, however, had its own group of chromosomes, the two groups being as before similar but non-identical in that they were constructed on different occasions. Only abdominal chaetæ were counted. 
Both diallels ran into difficulties. In the first diallel, infertility of females heterozygous for chromosome ( 12 ) resulted in five combinations receiving this chromosome from the mother failing to appear. In the second diallel the combination homozygous for chromosome (9) failed because of a lethal mutation, the culture which should have given combination (6) (9) failed completely and all flies carrying combinations which included chromosome (II) had to be rejected because of a major mutation which this chromosome (but not its counterpart in the first diallel) proved to carry. When homozygous this mutation reduced the number of chaetæ by an average of $I 9 . I$ as compared with its counterpart in the first diallel of this experiment, and when heterozygous by an average of $9 \cdot 7$. It and its normal allele appear therefore to show no dominance in respect of one another. It will be noted that the mutation appeared in a chromosome with recombination between regions $P$ and $Q$, i.e. very close to the centromere and possibly in the heterochromatin. One wonders, therefore, whether this change could have been the direct result of crossing-over in a place where it very rarely occurs. Crossing-over can bring about lethal mutations in the second chromosome (Wigan, $1949^{b}$ ) and has been suspected as a cause of visible mutations, including an incompletely dominant one (Mather and Harrison, r949). However this may be, the combination containing this chromosome clearly had to be omitted from the analysis of the results.

Both diallels were thus incomplete to an extent which precluded useful reconstruction by the missing-plot technique. No attempt has been made therefore to carry out any of the normal kinds of diallel analyses. Instead eight constants, four d's and four h's, have been fitted to the results separately for males and females in the two parts of the experiment. It will be seen that although five regions, A-a, P-p, Q-q, R-r and D-d are varied among the chromosomes of this experiment, $\mathrm{A}$ is always accompanied by $\mathrm{d}$ and a by $\mathrm{D}$. The constants we can find are thus $d_{a-d}, d_{p}, d_{q}, d_{r}, h_{a+d}, h_{p}, h_{q}$, and $h_{r}$, where $d_{a-d}$ and $h_{a+d}$ measure the joint effects of substituting $A+d$ for $a+D$. The values found from the results are shown in table 4 .

The values of the constants found from the two sexes in the same diallel agree quite well, but the two diallels show strikingly different values for several of the constants. Evidently here, to an even greater extent than in the first experiment, the genetical activity we can attribute to the chromosome regions we recognise is being affected by either the precise circumstances under which the diallel was carried out, or more likely by the precisc positions of the points of recombination. The relations that the changes in the regions $P, Q, R$ bear to each other support the attribution of the differences to variation in the points of recombination. The genetical activity of each region changes materially between the diallels, yet their total activity, $d_{p}+d_{q}+d_{r}$, is virtually constant, being $8 \cdot 12$ and 8.06 in the two diallels respectively. The sum of the three h's is also virtually the same in the two diallels 
(table 4), though here the three individual items change but little. Too much weight must not be placed on this evidence, as in the present experiment there is a strong negative correlation between the estimates of the constants attaching to the different regions, and especially between $d_{p}$ and $d_{q}$. For what it is worth, however, the evidence

TABLE 4

A. Additive and dominance components of variation in the second experiment.

Abdominals only

\begin{tabular}{|c|c|c|c|c|c|c|c|c|c|}
\hline & $d_{a-r}$ & $d_{p}$ & $d_{q}$ & $d_{r}$ & $h_{a}+d$ & $h_{p}$ & $h_{q}$ & $h_{\mathrm{r}}$ & s.e. \\
\hline $\begin{array}{c}\text { Ist Assay } \\
\text { Males } \\
\text { Females }\end{array}$ & $\begin{array}{l}1 \cdot 69 \\
0.53\end{array}$ & $\begin{array}{l}-0 \cdot 75 \\
-0.4^{2}\end{array}$ & $\begin{array}{l}6 \cdot 26 \\
6 \cdot 4^{2}\end{array}$ & $\begin{array}{l}1 \cdot 86 \\
2 \cdot 87\end{array}$ & $\begin{array}{l}0.57 \\
1.56\end{array}$ & $\begin{array}{r}0.27 \\
--0.22\end{array}$ & $\begin{array}{l}-1 \cdot 79 \\
-1 \cdot 30\end{array}$ & $\begin{array}{r}0.05 \\
-0.44\end{array}$ & $\begin{array}{l}\ldots \\
\ldots\end{array}$ \\
\hline Mean & $I \cdot 1 I^{*}$ & $-0.5^{8}$ & $6 \cdot 34^{*}$ & $2 \cdot 36 *$ & $1.07^{*}$ & 0.02 & $-1 \cdot 55^{*}$ & -0.19 & $0 \cdot 36$ \\
\hline $\begin{array}{l}\text { 2nd Assay } \\
\text { Males } \\
\text { Females }\end{array}$ & $\begin{array}{l}-0.18 \\
-1.65\end{array}$ & $\begin{array}{l}1 \cdot 24 \\
2 \cdot 46\end{array}$ & $\begin{array}{l}4 \cdot 88 \\
4 \cdot 49\end{array}$ & $\begin{array}{l}\mathrm{I} \cdot 4 \mathrm{O} \\
\mathrm{I} \cdot 65\end{array}$ & $\begin{array}{l}0 \cdot 61 \\
1 \cdot 01\end{array}$ & $\begin{array}{l}-0.25 \\
-0.34\end{array}$ & $\begin{array}{l}-1 \cdot 35 \\
-1 \cdot 31\end{array}$ & $\begin{array}{l}-0 \cdot 24 \\
-0.44\end{array}$ & $\begin{array}{l}\ldots \\
\cdots\end{array}$ \\
\hline Mean & $-0.9^{1 \dagger}$ & I $85^{*}$ & $4^{-69^{*}}$ & $1 \cdot 5^{2} *$ & $0.8 I^{*}$ & $-0 \cdot 29$ & $-1 \cdot 33^{*}$ & -0.34 & $0 \cdot 36$ \\
\hline Grand Mean & $0 \cdot 10$ & $0.63 \dagger$ & $5.51^{*}$ & I. $94^{*}$ & $0.94^{*}$ & -0.13 & $-1 \cdot 44^{*}$ & -0.27 & $0 \cdot 25$ \\
\hline
\end{tabular}

B. Comparison of constants from 1 st and 2 nd experiments.

Abdominals only

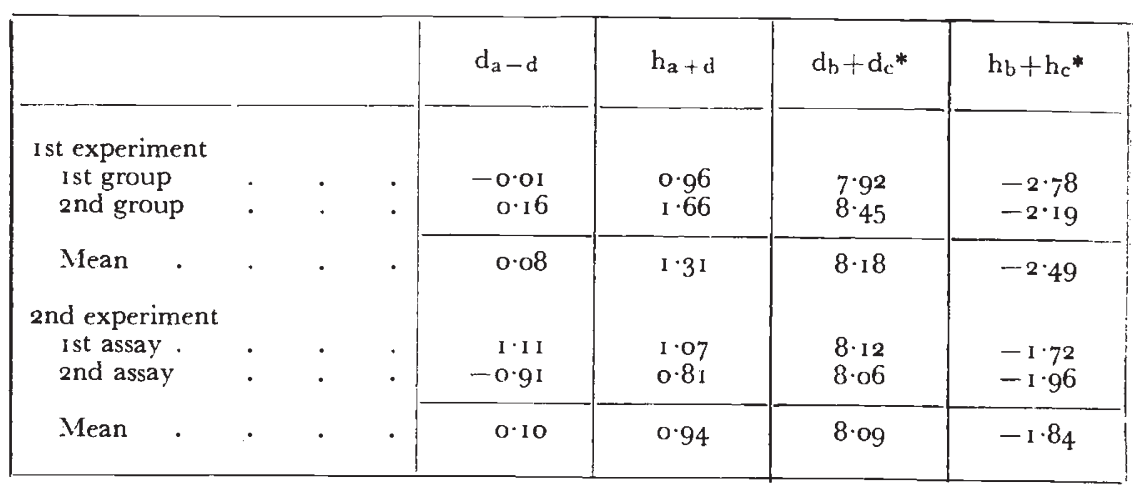

* Regions $\mathrm{B}+\mathrm{C}=\mathrm{P}+\mathrm{Q}+\mathrm{R}$.

suggests a virtually constant amount of genetic activity being subdivided in different ways in the two diallels, as would be expected from variation in the points of recombination.

A different subdivision of this portion of the chromosome can be seen in the first experiment, for it will be recalled that regions $P$, $\mathrm{Q}$ and $\mathrm{R}$ jointly cover the same length of chromosome as do regions $\mathrm{B}$ and $\mathrm{C}$. None of the individual regions match in respect of genetic activity in the two experiments and there is no reason why they should, but the total again agrees well in respect of both $d$ and $h$ 
activity (table $4 \mathrm{~B}$ ). The fact that $\mathrm{d}_{\mathrm{c}}$ is less than $\mathrm{d}_{\mathrm{r}}$, although region $\mathrm{R}$ presumably forms but part of $\mathrm{C}$ (fig. I) suggests that despite the selection practised on the parental $\mathrm{H}$ and $\mathrm{L}$ lines, there is still a modicum of balancing in this part of the chromosome, $\mathrm{C}$ carrying some genes tending to reduce chaeta number and $\mathrm{c}$ some tending to increase it. The same is suggested by the negative value for $d_{p}$ in the first diallel, though admittedly this is not a fully significant departure from zero. The values for $\mathrm{d}_{\mathrm{a}-\mathrm{d}}$ and $\mathrm{h}_{\mathrm{a}+\mathrm{d}}$ when compared over the two experiments are more variable than the sum of activities of the middle portion of the chromosome. This is perhaps understandable of a difference depending on two regions both long on the genetical map and delimited by points of recombination which vary simultaneously and independently of one another.

One further point remains to be made about the results of the second experiment. With the exception of $d_{p}$ in the first diallel all the $d$ values depart significantly from zero, so that there is evidence of every region being active. In neither diallel do $h_{p}$ and $h_{r}$ depart significantly, but $\mathrm{h}_{\mathrm{a}+\mathrm{d}}$ and $\mathrm{h}_{\mathrm{q}}$ are significant in both.

\section{THE THIRD EXPERIMENT}

This, too, consisted of two diallels, the first including the six chromosomes (I) and (I3)-(I7), and the second the six chromosomes (2) and (18)-(22) as listed in table $I$. Thus both can provide information on the activities of regions $\mathrm{X}-\mathrm{x}, \mathrm{Y}-\mathrm{y}$ and $\mathrm{Z}-\mathrm{z}$, but the effects of regions $A-a, D-d$ and R-r contribute to the overall difference between the diallels and so are confounded with one another, with any effect of difference in the precise points of recombination delimiting regions $\mathrm{X}, \mathrm{Y}$ and $\mathrm{Z}$ and with any difference of environmental effects between the two diallels. It is thus profitless to discuss anything but the overall effects of $\mathrm{X}, \mathrm{Y}$ and $\mathrm{Z}$ in this experiment.

In the first diallel five cultures failed. The mean number of abdominal chaetæ were taken as equal to those from the reciprocal crosses in four cases which would have yielded heterozygous combinations. For the abdominals in the fifth case (which would have given a homozygous combination), and for the sternopleurals in all five cases mean counts for flies raised specially on a different occasion were used to complete the diallel table. No culture failed entirely in the second diallel though in a few cases here, as in the first one, less than the usual io flies appeared. The mean count had then to be based on fewer than the customary number.

An analysis of variance of the results was carried out similar in principle to that in the first experiment. No attempt was made, however, to separate the sum of squares due to dominance from that due to the additive variation, the six components $\left(d_{x}, d_{y}, d_{z}\right.$ and $\mathrm{h}_{\mathrm{x}}, \mathrm{h}_{\mathrm{y}}, \mathrm{h}_{\mathrm{z}}$ ) being fitted simultaneously. Furthermore, as has been seen, the difference between the diallels could not be ascribed simply 
to difference in background, or group of chromosomes. The results of the analysis of variance are shown as mean squares in table 5, their most striking feature being the close similarity they bear to those of the first experiment. Taking the abdominals first, the mean square reciprocal difference is 3.22 as compared with the earlier figure of $3.5 \mathrm{I}$. Not being significant, this item was pooled with the high order interaction to give an error variance of $2 \cdot 96$, which is again closely similar to that of the earlier experiment.

TABLE 5

Analysis of variance of results from the third experiment

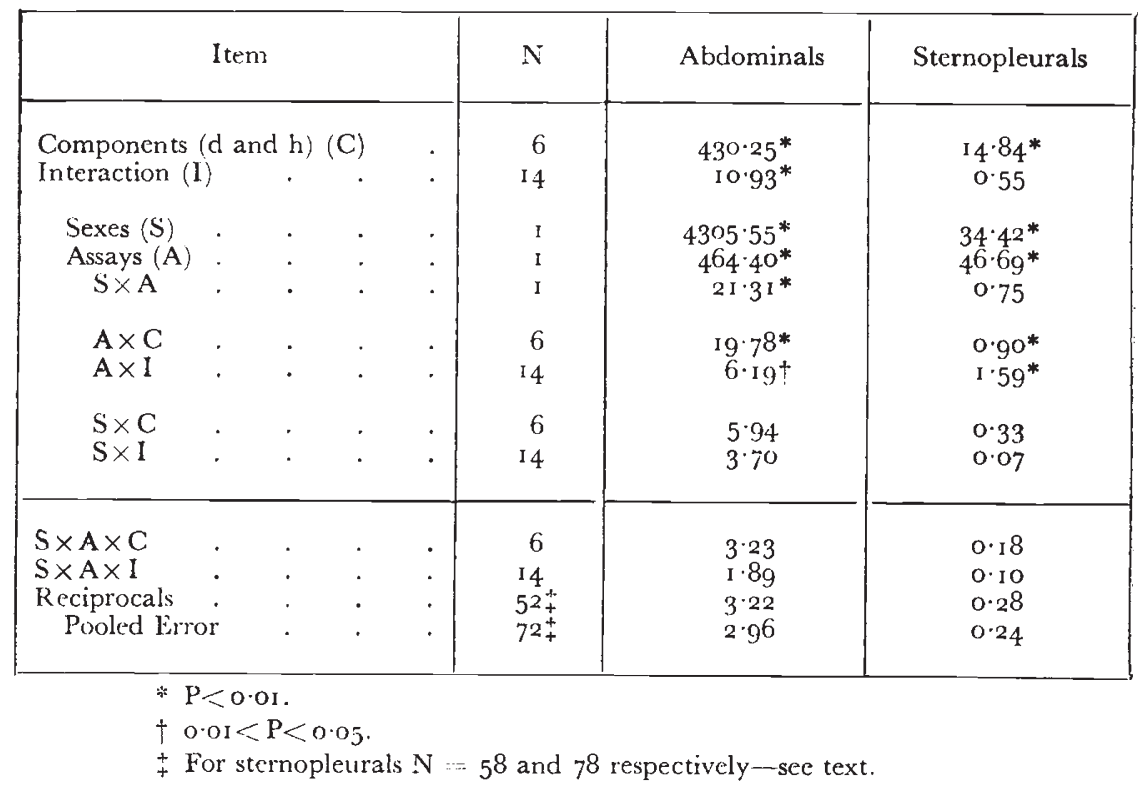

Once again, not only the item for components of variation, but also that for residual interaction is significant, being in fact of the same order of size as in the first experiment. Furthermore the interaction of components with sex and diallels at an average of 12.85 is much the same as the corresponding average (of $\mathrm{B} \times \mathrm{C}, \mathrm{G} \times \mathrm{C}$, and $\mathrm{S} \times \mathrm{C}$ ) which was II.74 in the first experiment. Thus once again the genic interaction within chromosome III is of the same size as the interaction between this chromosome on the one hand and its fellows and environmental differences on the other. There is some hint again of the interaction within the chromosome varying with the background.

Much the same can be said of the genic activity as expressed in the number of sternopleural chaetæ, the chief difference from the first experiment being that the interaction of components and other effects is now more nearly like the residual interaction itself in size.

The estimated values of the actual components of genic variation are set out in table 6 . The total effects on the abdominals $\left(d_{x+y+z}\right.$ 
and $h_{x+y+z}$ ) vary somewhat between the two diallels, but the average additive effect of the two diallels at 6.53 agrees well with the sum (6.15) of the effects of regions $\mathrm{p}$ and $\mathrm{q}$, which cover the same length of chromosome in the second experiment. No similar comparison is possible for the sternopleurals which were not followed in the second experiment. The individual components significantly demonstrate action only in region $\mathrm{Y}-\mathrm{y}$, but the significant item for interaction remaining

TABLE 6

A. Additive and dominance components of variation in the third experiment

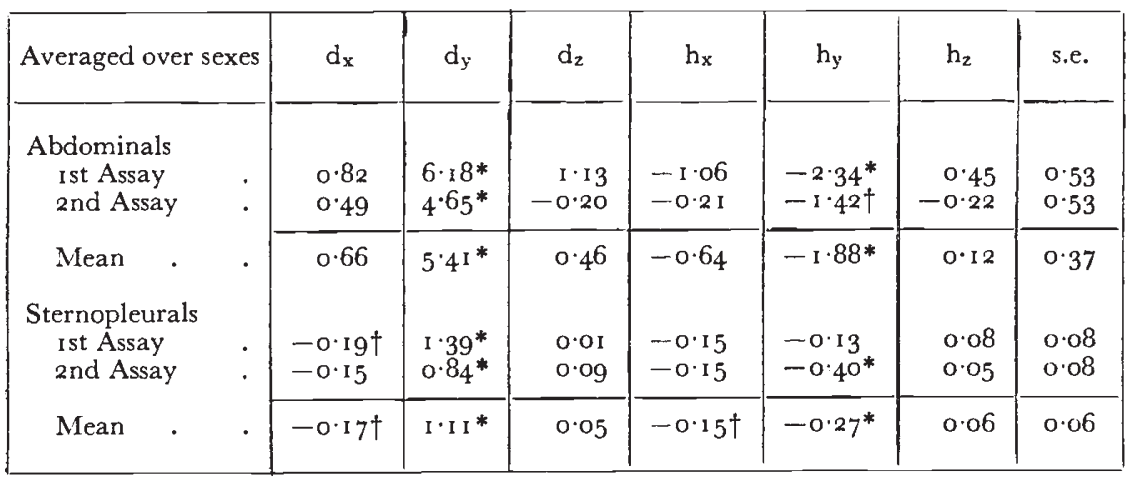

$* \mathrm{P}<0.01 . \quad \dagger 0.01<\mathrm{P}<0.05$.

B. Comparison of constants from second and third experiments

\begin{tabular}{|c|c|c|c|c|c|c|}
\hline & & & \multicolumn{2}{|c|}{ 2nd experiment } & \multicolumn{2}{|c|}{$3^{\text {rd }}$ experiment } \\
\hline & & & $\mathrm{d}_{\mathrm{p}+\mathrm{q}}$ & $\mathrm{h}_{\mathrm{p}+\mathrm{q}}$ & $\mathrm{d}_{\mathrm{x}+\mathrm{y}+\mathrm{z}}$ & $h_{x}+y+z$ \\
\hline $\begin{array}{l}\text { Ist Assay } \\
\text { 2nd Assay }\end{array}$ & . & $\cdot$ & $\begin{array}{l}5 \cdot 7^{6} \\
6 \cdot 54\end{array}$ & $\begin{array}{l}-\mathrm{I} \cdot 53 \\
-\mathrm{I} \cdot 62\end{array}$ & $\begin{array}{l}8 \cdot 12 \\
4 \cdot 94\end{array}$ & $\begin{array}{l}-2 \cdot 96 \\
-\mathbf{I} \cdot 85\end{array}$ \\
\hline Mean & - & - & $6 \cdot 15$ & $-\mathrm{I} \cdot 5^{8}$ & $6 \cdot 53$ & $-2 \cdot 40$ \\
\hline
\end{tabular}

in the analysis of variance after fitting the individual components must be taken as evidence that even so regions $\mathrm{X}-\mathrm{x}$ and $\mathrm{Z}$.-Z nevertheless share some activity since they (or at least one of them) interact in effect with region $\mathrm{Y}-\mathrm{y}$.

\section{THE FOURTH EXPERIMENT}

The design of the earlier experiments was such that the effects of the different regions of the chromosome were not orthogonal to one another with the consequence that they could be assessed only by the successive fitting of constants. This last experiment utilised eight chromosomes representing every combination of the three compound regions A-a, PQ-pq and RD-rd. The effects of these compound regions and also their interactions can thus be assessed individually 
by an analysis of variance using the customary orthogonal functions. Only homozygous combinations were used and only d components of variation can therefore be estimated. Two groups of such chromosomes, constructed separately, were used and the whole experiment duplicated, so that there were in effect four observations of each genotype. No combination failed in all four replicates, but a few

TABLE 7

A. Analysis of cariance and covariance-fourth experiment

\begin{tabular}{|c|c|c|c|c|}
\hline Item & $\mathrm{N}$ & Abdominals & Stcrnopleurals & $\begin{array}{l}\text { Stps. corrected } \\
\text { for regression } \\
\text { on abds. }\end{array}$ \\
\hline $\begin{array}{l}\text { Adiditive effects }(\mathrm{C}) \\
\text { Interaction }(\mathrm{I})\end{array}$ & $\begin{array}{l}3 \\
4\end{array}$ & $\begin{array}{c}1028 \cdot 78^{*} \\
2 \cdot 80\end{array}$ & $\begin{array}{l}41 \cdot 33^{*} \\
0.30\end{array}$ & $\begin{array}{l}21 \cdot 91 * \\
0.27\end{array}$ \\
\hline $\begin{array}{l}\operatorname{Sex}(S) \\
S \times C \\
S \times I\end{array}$ & $\begin{array}{l}1 \\
3 \\
4\end{array}$ & $\begin{array}{r}1718 \cdot 10^{*} \\
10 \cdot 17^{*} \\
4 \cdot 12 \dagger\end{array}$ & $\begin{array}{c}24.63^{*} \\
0.48 \\
0.89 !\end{array}$ & $\begin{array}{l}0.16 \\
0.32 \\
0.85\end{array}$ \\
\hline $\begin{array}{l}\text { Error (between cultures) } \\
\text { Error (within cultures) }\end{array}$ & $\begin{array}{l}20 \\
20\end{array}$ & $\begin{array}{l}1 \cdot 40 \\
1 \cdot 45\end{array}$ & $\begin{array}{l}0.56 \\
0.21\end{array}$ & $\begin{array}{l}0.59 \\
0.22\end{array}$ \\
\hline
\end{tabular}

B. Additive components of variation-fourth experiment

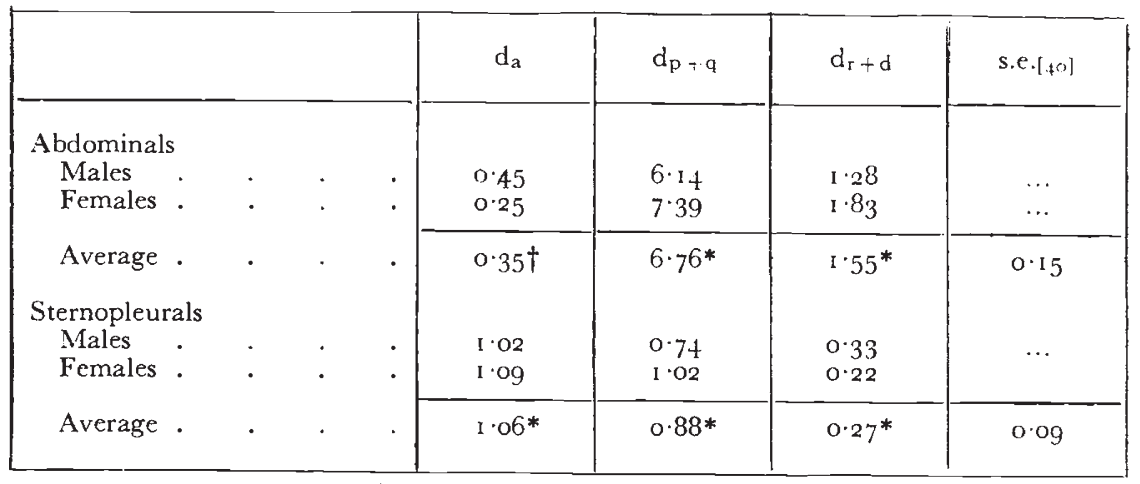

s.e. derived from the pooled error items.

* $\mathrm{P}<0.01 . \quad+0.01<\mathrm{P}<0.05$.

failed in some of them. Thus there are fewer degrees of freedom for error than would otherwise have been the case.

The analysis of variance (table 7) shows the error variation to be lower for abdominals in this than in the earlier experiments, that for sternopleurals being much as before. The main $\mathrm{d}$ components are significant for both characters, as is the sex difference. Interactions of activity of the three compound regions are significant for neither character, though the sex-component interaction is significant in the case of the abdominals. While this experiment therefore fails to repeat the earlier ones in showing clear interactions within the chromosomes, it fully supports them in showing that whatever interactions of 
this kind there may be they are certainly no larger than those between chromosomes. There is again no evidence of any special interaction within the chromosome.

The value of $d_{a}$ is somewhat smaller for abdominals and larger for sternopleurals than had been found earlier, but the other $d$ values were of about the size expected from earlier experience.

An analysis of covariance was carried out to test the degree of dependence of variation in sternopleurals on that in abdominals. The whole of the sex difference in sternopleurals can be accounted for by relation to the sex difference in abdominals, but only half the effect of the three $d$ components can be taken up in this way. The genic activity of the third chromosome is thus not equivalent for these characters. Some genes may affect both characters similarly, but the gene systems controlling them are certainly not identical : the characters are capable of independent genetic adjustment at least in part.

\section{DISCUSSION}

In the first experiment, chromosome III was subdivided into four regions all of which proved to be genetically active in their effects on the number of abdominal chaetæ, so requiring the postulate of at least four genes. In the second experiment the minimum of genes was increased, since two of these three regions were jointly subdivided into three, all of which again proved to be active. Furthermore, although the total activity of regions $\mathrm{P}, \mathrm{Q}$ and $\mathrm{R}$ appeared constant over the two parts of this experiment, its distribution between the three regions differed in the two parts of the test. The precise point of recombination is thus important in determining the distribution of activity between the regions, so that a minimum of three genes between these three regions would appear insufficient to account for the observation. The second experiment therefore raises the minimum necessary in the whole chromosome to more than five, though whether to six or seven depends on a more detailed and therefore more debatable interpretation of the second experiment. In the third experiment regions $P$ and $Q$ were again jointly subdivided into three, but this adds little to our information as only one of the new regions, $Y$, shows marked activity, the evidence of activity in $\mathrm{X}$ and $\mathrm{Z}$ being inconclusive.

It is important, too, that apart from the last subdivision not merely did each fractionation of the chromosome reveal more genes, but every region proved to be active. It is unlikely therefore that the minimum number of six or seven would not be raised still further by further analysis of the chromosome. We are in fact led to picture the chromosome as being genetically active in respect of abdominal chaeta number along the whole or at least great parts of its length; to picture it as being in other words truly polygenic in its activity. The activity of any region of the chromosome is then not an attribute of a single gene but of that constellation of genes which the region 
happens to contain. The region is to be regarded as an effective factor for the purposes of the experiment, and a factor which could be further broken down when the region is fractionated by further recombination. Regions $\mathrm{B}, \mathrm{Q}$ and $\mathrm{Y}$ admittedly stand out from the rest by reason of the great activity which they display relative to their lengths on the genetical map, so suggesting a major concentration or even a single locus of major effect. Reference to fig. I shows, however, that $\mathrm{B}$ and $\mathrm{Y}$ certainly include the region of chromosome near the centromere, while either $\mathrm{P}$ or $\mathrm{Q}$ must also do so. Now recombination is rare near the centromere so that the genetical map greatly underestimates the physical length of chromosome regions in this neighbourhood. Indeed if we seek to relate activity to length in the mitotic chromosome, the high activity of these centromere regions ceases to be noteworthy. We can thus understand the distribution of activity between the various regions if we regard the polygenic system from which the activity springs as distributed roughly evenly along the physical length of the chromosome. Such an approximately even distribution would not be surprising, and indeed might even be anticipated given that any sizeable block of heterochromatin near the centromere is, mitotic length for length, about as polygenically active as the euchromatin of more distal regions.

It has sometimes been proposed (e.g. by Reeve and Robertson, 1953) that far from such continuous variation being mediated by polygenic systems, it is governed by a few loci of major effect, the continuity of variation springing from the existence of a range of socalled "iso-alleles" at each locus. This postulate meets with considerable difficulty in explaining even the results of selection experiments for which it was proposed (Mather, r954): it is impossible to reconcile with the results of the present survey.

There might still be some justification for treating the chromosome, or some large section of it, as a unit (though it could not be called a gene without such a gross straining of the term as to render it meaningless) if the genes within it displayed some unique form of interaction peculiar to them because of their physical association. Such interaction, depending on special physical relations of the interacting entities, must be expected within very short regions of chromosomes and serve to define genes (Mather, I946, I 954; Goldschmidt, I95I) ; and they are indeed known in the phenomenon known as pseudoallelism. There is, however, no trace of them over the longer lengths of chromosome with which we are dealing. The genic interactions detectable within chromosome III seems to be no greater than, and no different from, those between the genes of this and other chromosomes.

There is good evidence that the genes in several of the segments show dominance. In the regions $\mathrm{B}, \mathrm{Q}$ and $\mathrm{Y}$ the heterozygous combination is nearer to the combination homozygous for the group of genes from the $\mathrm{L}$ parent. The $\mathrm{h}$ component of activity is nevertheless 
lower in value than the $\mathrm{d}$, so that either the genes in question are only partly dominant or there exist within the group some genes with dominance in the opposite direction despite the overall preponderance of dominance for the lower chaeta number. There is also a suggestion of dominance in the low direction of genes within the $\mathrm{X}$ segment and of dominance in the high direction of those in A and D. Thus, as would be expected in a polygenic system (Mather, I 943), dominance is not completely unidirectional though it is of interest that again, as Fisher (1930) has suggested would be the case, it is preponderantly in the direction away from the heavier and more effective selection, chaeta number of the $\mathrm{H}$ line having been raised more by the selection practised in its production than $\mathrm{L}$, was lowered.

Turning to the sternopleural chactæ we note that a number of the segments show genic activity in respect of this character, too, and indeed the situation is very much the same as for the abdominals. That the differences in activity between the pieces of chromosome derived from $\mathrm{H}$ and $\mathrm{L}$ are relatively not so great as those in respect of the abdominals is suggested by two comparisons. In the first place, the ratio borne by the components' mean square to the error mean square is higher for abdominals than sternopleurals in every analysis of variance and markedly higher in some. And secondly, the d components for the sternopleurals are lower relative to the overall mean number of these chaetæ than for the abdominals. Segments B, $Q$ and $Y$ show the greatest activity in respect of sternopleurals as in respect of abdominals, but this is to be expected if the large effect is due to the great physical length of these regions. Otherwise there is little evidence of a correlation between sternopleural and abdominal activity. In other words, we have no grounds for believing that the sternopleural differences reflect merely a pleiotropic activity of the gene system governing the number of abdominal chaetx, and the analysis of variance in the fourth experiment bears this out. The occurrence of some pleiotropic activity cannot be ruled out, and Cocks (1954) has indeed obtained some evidence of it; but the characters are evidently controlled by at least partly different genic systems so that they can be adjusted separately by selection. The correlated responses of sternopleural chacta number to selection for abdominals would then be in the main due to the linkage relations of the polygenic systems controlling them, as has been amply demonstrated (Mather and Harrison, 1949) for this and other characters in earlier selection experiments.

\section{SUMMARY}

The distribution of genetic differences between the third chromosomes of two selected lines of Drosophila melanogaster was investigated in respect of number of abdominal chaetæ. (for which the selection has been practised) and number of sternopleural chacta. By means of a marker stock, recombinant chromosomes were constructed 
which consisted of known portions of the two selected third chromosomes but which themselves carried no marker genes. The six regions into which the chromosome was thus divided were tested for contributions to additive variation, for dominance and for genic interaction, and the variation of these effects with sexes and with genetic background was observed. All regions showed genetic activity and most showed dominance effects. Genic interaction was detected within the chromosome but it appeared to be of no greater effect than the interaction of genes in the third chromosome with genes in other chromosomes. The activity was greatest in the region of the centromere when related to the genetical map, but appeared to be more or less evenly distributed along the chromosome when related to the physical lengths of the regions.

At least six genes must be involved in the third chromosome's contribution to the differences between the two selected lines, and the data are most readily interpreted in terms of a polygenic system spread along the whole chromosome. They cannot reasonably be reconciled with the postulate of a very few loci of major and complex effect each varying to give a range of iso-alleles. Though some genes may affect abdominal and sternopleural chaetæ simultaneously, the genetic systems governing the two are at least in part distinct from one another. The characters can thus be adjusted separately by selection. The correlated responses in the one to selection for the other must depend in the main on the linkage relations of the systems rather than pleiotropy of gene action.

\section{REFERENCES}

COCKs, B. 1954. Polygenic systems controlling the expression of major mutant genes which affect chaeta number in Drosophila melanogaster. Heredity, 8, $13-34$. Darlington, C. D. 1939. The Evolution of Genetic Systems. Univ. Press, Cambridge. DARLington, C. D. I956. Natural populations and the breakdown of classical genetics. P.R.S., $\mathrm{B}, 145,350-364$.

Fisher, R. A. 1930. The Genetical Theory of Natural Selection. Clarendon Press, Oxford.

Goldschmidr, R. B. 1951. Chromosomes and genes. Cold Spring Harbor Sym. Quant. Biol., I6, I-Io.

HARRISON, B. J. I953. Reversal of a secondary sex character by selection. Heredity, $7,153-164$.

HAYMAN, в. I. I 954a. The analysis of variance of diallel tables. Biometrics, ro, $235^{-2} 44$.

HAYMAN, B. I. 1954 $b$. The theory and analysis of diallel crosses. Genetics, 39, 789-8og.

JINKS, J. L. 1954. The analysis of continuous variation in a diallel cross of Nicotiana rustica varieties. Genetics, 39, 767-788.

MATHER, K. 1942. The balance of polygenic combinations. 7. Genet., 43, 30 $30-36$.

MATHER, K. 1943. Polygenic inheritance and natural selection. Biol. Revs., i8, $32-64$.

MAther, K. 1946. Genes. Sci. 7. R. Coll. Sci., 16, 63-7 I.

mather, K. I949. Biometrical Genetics. Methuen, London. 
Mather, K. I954. The genetical units of continuous variation. Proc. gth Int. Cong. Genetics, Caryologia, Suppl. to Vol. 6, I06-1 23.

MATHER, K., AND harRison, B. J. I949. The manifold effect of selection. Heredity, $3, \mathrm{I}-52$ and $\mathrm{I} 3 \mathrm{I}-\mathrm{I} 62$.

MATHER, K., AND VINES, A. I952. The inheritance of height and flowering time in a cross of Nicotiana rustica. Quantitative Inheritance, ed. E. C. R. Reeve and C. H. Waddington. H.M.S.O., London, pp. 48-8o.

REEVE, E. C. R., AND ROBERTSON, F. W. I953. Studies in quantitative inheritance II. f. Genet., 5I, 276-316.

WIGAN, L. G. I949a. The distribution of polygenic activity on the X-chromosome of Drosophila melanogaster. Heredity, 3, 53-66.

WIGAN, L. G. I949b. Chromosome regions which give new variation by crossingover. Proc. 8th Int. Cong. Genetics. Hereditas Suppl. Vol., pp. 686-687. 